\title{
Different Approaches Towards Electricity Transmission Expansion
}

\author{
JUAN ROSELLÓN* \\ Centro de Investigación y Docencia Económicas (CIDE) and Harvard University
}

\begin{abstract}
There is an intense debate regarding the best way to attract investment for the long-term expansion of an electricity transmission network. We study three hypotheses: the long-term financialtransmission-right hypothesis; the incentive-regulation hypothesis; and the market-power hypothesis. The first approach derives optimal transmission expansion through auctions of longterm financial transmission rights by an independent system operator. The second provides a Transco with incentives to expand the network by making it face the entire social cost of congestion. The third approach defines optimal transmission expansion according to the strategic behavior of generators. This paper discusses the analytical and practical strengths and weaknesses of each approach.
\end{abstract}

\section{Introduction}

As in other infrastructure industries, the transportation or "transmission" network is vital for the development of the electricity industry. Transmission capacity shortages hinder the development of other electricity segments (such as generation) resulting in reductions of social welfare due to the high electricity prices paid by end users. The development of electricity transmission requires adequate incentives to solve short-run congestion problems, recuperate long-term fixed costs, and investment to expand the network.

Generally, there is a consensus in the economics literature about calculating the marginal cost of electricity transmission usage, and therefore resolving short-term congestion. As shown in Hogan (2002a), the difference in electricity prices between two nodes in a power-flow model defines such a price. However, there is an intense debate regarding how to best attract investment for long-term expansion; that is, how to solve the dual (opposite) objectives to congest the network in the short run and to expand it in the long run. International practice reveals several divergent mechanisms that have been used to try to solve these issues (see Hunt, 2002, and Woolf, 2003). While basic regulation has

* Mailing addresses: U.S.A.: John F. Kennedy School of Government, 79 JFK Street, B-314, Cambridge, MA 02138, U.S.A. Email: juan rosellon@harvard.edu Mexico: Carret. México-Toluca 3655, Lomas de Santa Fé, C.P. 01210, México D.F. Mexico. Email: juan.rosellon@cide.edu I am grateful to William Hogan and Ingo Vogelsang for their insightful suggestions and discussions. I also thank an anonymous referee for helpful comments. All remaining errors are my own. The research reported in this paper was supported by the Comisión Reguladora de Energía in a grant to CIDE. 
been applied in England, Wales and Norway to guide the expansion of the transmission network, a mixture of planning and auctions of long-term transmission rights has typically been used in northeastern United States. A combination of regulatory mechanisms and merchant incentives is used in the Australian market.

Under constant returns to scale, conditions for the optimal capacity expansion of the transportation segment of an infrastructure industry are well known. At the optimum, the per-unit marginal cost of new transportation capacity must be equal to the expected congestion cost of not adding an additional unit of capacity (Crew, Fernando and Kleindorfer, 1995). Optimal capacity utilization could be achieved through proper pricing (Wilson, 1993). However, electricity transmission presents special characteristics - beyond economies of scale and cost subadditivity - that complicate the regulatory analysis of appropriate incentives for a transmission network. The above transportation capacity optimal conditions do not apply under such special characteristics.

Externalities in electricity transmission are mainly due to loop-flow problems that arise through interactions in the transmission network. These interactions are governed by Kirchhoff's law that states that electricity flows follow the transmission path of least resistance. In a direct current (DC) model (a linear representation of power flows), if an indirect path is twice as long as a direct path, so is the resistance. (For example, in a threenode network an electricity unit produced at one node will generate a $1 / 3$ flow along the indirect path, and a 2/3 flow along the direct path. See Joskow and Tirole, 2000, and Léautier, 2001).

The effects of loop flows imply that it is not possible to define the "available transmission capacity" at a point in time without the existence of complete information about the use of the network at that time. Likewise, transmission opportunity costs and pricing critically depend on the marginal costs of power at each location. Energy costs and transmission costs are not independent since they are determined simultaneously in the dispatch and the spot market. As explained by Bushnell and Stoft (1997), the external benefits of transmission investments are not appropriable and certain transmission investments in a particular link might have negative externalities on the capacity of other (maybe remote) transmission links. Paradoxically, the addition of new transmission capacity can sometimes reduce the total capacity of the network (see Hogan, 2002b).

In this context, the standard theory of public economics (as in Laffont, 1989) suggests that one way to proceed with a line expansion is to make the investor pay for the negative externalities generated. To restore feasibility, the investor must buy back sufficient transmission rights from those who hold them initially (as in Bushnell and Stoft, 1997), or an independent system operator (or dispatcher) must retain some transmission rights in an auction for long-term rights to ensure that the expansion project does not violate the property rights of the initial transmission right holders. Essentially, this is the first proposal we survey in Section 3 (3.3 through 3.5).

In Section 4, we analyze a regulatory alternative that seeks to solve the transmission expansion problem in a different institutional framework. Operation and ownership of the transmission company are carried out by a Transco that is regulated through benchmark or price regulation so as to provide it with incentives to invest in the development of the grid in order to avoid congestion. The price regulation proposal differs from the transmission rights approach in that it tries to derive a cost and production function for transmission, while the transmission rights approach avoids dealing with this issue due to the practical impossibility of tracing the exact physical flows of electrons. 
In Section 5, we study a third proposal that seeks to derive optimal transmission expansion from the power-market structure of electricity generation. Based on real options analysis, this approach involves finding the joint probability distribution for both transmission and generation outcomes. This joint probability distribution is then used to calculate the net present value of the transmission expansion projects.

The plan of the paper is as follows. Section 2 surveys the different electricity markets and the basic elements of optional institutional designs for electricity transmission operation. Section 3 presents the basics of the power flow model (3.1) and of the locational price theory (3.2). These concepts are fundamental to understand the distinct transmission expansion mechanisms presented from 3.3 through Section 5. Such mechanisms build on the institutional settings, and the management of the short-run spot energy market by the system operator. Concluding remarks are given in Section 6.

\section{Market architecture and the system operator's institutional design}

The analysis of mechanisms for transmission expansion depends upon the type of electricity market design. The institutional structure of the system operator and its relationship with the transmission network are key components that define the alternatives that will attract new investment. We now analyze these basic market design elements for the electricity sector.

\subsection{Market architecture of the electricity sector}

Market architecture is the discipline that analyzes the details of market organization that affect the performance of economic agents. Economists design the features of an "economic building" (the market) using several theoretical and practical mechanisms. The technology available to the architect-economist constrains the design possibilities.

Wilson (2002) analyzes these topics for the electricity industry, which is plagued by incomplete and imperfect markets, and identifies the issues that complicate efficient market design. Electricity is an economic good that is expensive to store. Its transmission from generation plants to consumption centers is usually carried out in complex meshed networks that can be affected by capacity constraints. Due to the nature of electricity-flow, rights in the electricity transmission sector are difficult to define. Other obstacles for market design arise from the need of energy and transmission provisions to meet demand in real time and reserves to meet random demand shocks.

Power generation and electricity marketing are generally considered to be areas in which competition might work, but transmission and distribution are still natural monopolies. Technological advances in thermoelectric generation have recently turned thermal generation into a potentially competitive activity. However, hydro electrical and nuclear generation typically retain huge sunk costs, and cost subadditivity. With an adequate regulatory framework and institutional structure, vertical separation among production, throughput, coordination and marketing activities usually results in a competitive wholesale electricity market structure.

A continuous spot market is typically needed but its operation must be coordinated with that of a complex transmission system. Since electricity can hardly be stored, a system operator (SO) is needed in order to coordinate real-time operations from both an engineering scope and an economic perspective. According to Hogan (1999a) and 
Borenstein (2002), the SO must be allowed to offer the economic dispatch (pool) service based on marginal-cost power pricing. Participation in such dispatch should be voluntary. The pool service provides the means by which generation costs are minimized through the merit-ordering of bids from generators, and establishes the price-bid of the last dispatched generator as the market uniform price. Pay-as-bid auctions are an alternative discriminatory-auction mechanism. Wolfram (1999) analyzed the pay-as-bid auction mechanism in the "Programme to Reform the Electricity Trading Arrangements" (RETA) for the United Kingdom electricity industry, and argued that it might lead to less competition and higher prices than the uniform-price auction.

The SO may handle a sequence of day-ahead, and real-time operations, as well as longer time frames. The system's stability can be maintained through the management of a pre-arranged system of generation reserves. The SO achieves a continuous balance using the submitted offers and several time-differentiated categories of reserves including regulation capacity, operating reserves (spinning and non-spinning), replacement reserves, and reliability-must-run.

Contracts for differences also provide generators and purchasers the freedom to carry out bilateral contracts, and ensure that any imbalance in production or consumption is settled though the pool price. The parties mutually insure each other covering the difference between the contracted and market prices. Bilateral contracts may be physical contracts for actual production or financial contracts. According to Wilson (2002), in mature systems the pattern of energy transactions is $80 \%$ contracted long term, $20 \%$ dayahead, and less than $10 \%$ spot.

\subsection{The system operator's institutional design}

According to Wilson (2002), there are four markets that characterize a complete market for electricity: the forward transmission market, the spot energy market, the forward energy market (or market of bilateral contracts), and the forward market for reserves. Such markets have complex interactions that complicate the analysis of the optimal incentives to expand transmission capacity, and energy supply and reserves. They affect the ability of the SO to achieve these tasks and also affect the optimal behavior of generators in the spot energy and forward capacity markets.

The SO has a (natural) monopoly over its functions. However, other design issues arise regarding the SO's organization and institutional characteristics such as governance, incentives, regulation, and economic objective function. Vogelsang (2001) argues that the objective function of an SO should consider the minimization of difference in locational prices.

Wilson (2002) presents three possible structures for an SO designed to reach an equilibrium for the four electricity markets. Each one might determine the way expansion in transmission could be achieved. The first structure is an independent system operator (ISO), different from the company that owns the transmission grid, that is decentralized, and intrudes to the least possible extent in the four mentioned markets. The second is a centralized ISO that controls and coordinates the four markets. The third is an integrated company (or Transco) that combines ownership of the transmission network with system operations. Hybrid designs that allow for different degrees of centralization are also possible, for example, central control of transmission and reserves by an ISO together with forward markets for energy. 
A centralized ISO imitates vertically integrated functions through an overall optimization of operational decisions and long-term contracting among participants. It attempts a simultaneous optimization of all four electricity markets. This minimizes the costs of ensuring reliability and coordinating generation, transmission and reserves. Likewise, in a centralized system the ISO has full control of the real-time dispatch; reserve options are not voluntary. Additionally, the ISO can reduce flows or produce counter flows by directing generators to reduce or expand their production according to bidding procedures and the use of locational prices.

Wilson (2002) believes that centralization is preferable when vigorous competition and adequate technical and economic optimization exist. However, he argues that centralization does not provide the proper incentives for cost minimization since pool bids do not always reflect actual costs. On the contrary, a decentralized ISO would manage transmission and reserves with little intrusion into energy markets. A decentralized ISO should permit a sequential optimization of the four electricity markets with voluntary participation of market agents. Wilson avers that decentralization is better when incentives for cost minimization and good scheduling decisions by each participant's pool are more important than coordination in electricity markets. However, Hogan (1995) argues that the dichotomy between centralized and decentralized ISOs is false: any decentralized market can be centralized through adequate definition of access and pricing, avoiding the risk of loss of coordination of a decentralized regime.

In practice, the ISO model has been used in Argentina, and most of Australia. System operation is carried out by the ISO and transmission ownership is carried out by another independent company, the Gridco. ISOs also exist in California, New England, New York, Pennsylvania-New Jersey-Maryland (PJM), and Texas. ISO practical experiences and proposals have been centralized. Recent United States, Mexican and Central American proposals to reform electricity sectors contain elements of a centralized ISO (see Federal Energy Regulatory Commission, 2002, and Secretaría de Energía, 2002). In the United States, the Federal Energy Regulatory Commission (FERC) issued a standard market design (SMD) in 2002 that requires transmission companies to join a Regional Transmission Organization (RTO) in an effort to promote vertical disintegration between transmission and generation. Regional planning is recognized as an important element of system expansion.

In the Mexican proposal, the ISO would operate a market for large consumers while the existing State utility would retain its vertical integration, and would provide public service exclusively for small consumers. The ISO would consider the bids of all plants in a pool - including those devoted to public service - and would dispatch them according to merit order. A forward energy market based on bilateral contracts exists in parallel.

The Transco approach is similar to a centralized ISO but with a dispatch controller that also owns the transmission network. Joskow (2000) hints that the decision between the two options is based on institutional conditions. In the United Kingdom, such conditions made the implementation of a Transco possible (National Grid Company). However, in the United States it is difficult to impose a Transco because of the property structure of the transmission network. Hogan $(1999 \mathrm{a}, \mathrm{b})$ believes that such a measure would result in many small regional Transcos with compatibility problems. However, Hunt (2002) favors the Transco approach since it is a profit-making entity that, as opposed to an ISO, is responsible for maintaining and expanding the transmission assets: "A Transco requires a serious board of Directors to see that it meets its financial responsibilities to shareholders" 
(Hunt, 2002, p.213). Joskow and Tirole (2002) also favor the Transco approach because the separation between transmission operation and system operation may lead to high coordination costs.

Assuming that the Transco model is complemented by the competitive policies of FERC's SMD, it could respond more appropriately to an incentive type of tariff regulation, and make better choices between short-run operational and long-term investment decisions. Hunt also recognizes that a Transco must be regulated carefully. If transmission rights created under a central planning transmission process were not auctioned, and the Transco retains the revenues from transmission charges, it could dispatch the system in a way that causes congestion. Hunt also believes that either in the ISO form or Transco form, transmission and system operation must be separated from generation to avoid conflicts of interest. In practice, the Transco model has been also employed in Spain and Scandinavia.

\section{Long term financial rights for transmission expansion}

We now describe the first proposal for transmission expansion. This "merchant" approach relies on an independent system operator to carry out auctions for long-term financial transmission rights. The ISO retains some unallocated rights to ensure that no particular transmission expansion proposals affect the original transmission property rights.

We first describe in sections 3.1 and 3.2 the basic elements of an equilibrium in the spot market from where the financial transmission right theory is derived. Building on these concepts, we present from 3.3 onwards the proposal based on long-term financial transmission rights.

\subsection{The economic dispatch model}

There is extensive literature, both in the economics and electrical engineering fields, describing the modeling set up for an equilibrium analysis of the electricity spot energy market (see Hogan, 2002b; Léautier, 2000; Joskow and Tirole, 2000). The typical framework is that of a centralized ISO seeking to maximize social welfare subject to transmission-loss and flow-feasibility constraints in a centralized spot market. In practice, this model is used in Argentina, Australia, and several regions in the United States (PJM, New York, Texas, California). FERC's SMD and the Mexican reform proposals also foresee the use of such a mechanism as well as the recent electricity market developments in Central America (see Federal Energy Regulatory Commission, 2002; and Secretaría de Energía, 2002).

Schweppe et al. (1988) offer a simplified presentation of the DC approximation model. Other representations are elsewhere available for alternating current (AC) systems and for "DC-load" models. (See Hogan, 2002b and Schweppe et al., 1988). Consider a power network with $N$ nodes and $L$ lines. For $n=1, \ldots, N$, let:

$q_{n}^{s}$ : real power generated (MWh) at node $n$

$q_{n}^{d}$ : real power consumed (MWh) at node $n$

$q_{n}=q_{n}^{s}-q_{n}^{d}:$ net real power load (MWh) at node $n$

$C S_{n}\left(q_{n}^{d}\right)$ : consumer surplus (MWh) at node $n$ 
$C_{n}\left(q_{n}^{s}\right)$ : generation cost (MWh) at node $n$

where $C S_{n}\left(q_{n}^{d}\right)$ and $C_{n}\left(q_{n}^{s}\right)$ are assumed to be continuously differentiable on $R$. For, $l=$ $1, \ldots L$, let:

$z_{l}:$ real oriented energy flow $(\mathrm{MWh})$ on line $l$

$K_{l}$ : capacity (MW) of line $l$

In vector notation, let $\mathrm{q} \in R^{n}$ be a vector of net injections, $\mathrm{z} \in R^{L}$ be a vector of real oriented flows, and $\mathrm{K} \in R^{L}$ a vector of capacities. The following technical constraints must be met in any power network:

Energy balance

$\sum_{n=1}^{N} q_{n}^{s}=\sum_{n=1}^{N} q_{n}^{d}+\widetilde{L}(\mathbf{z})$

where $\tilde{L}(\mathrm{z})$ are the transmission losses for $\mathrm{z} \in R^{L}$. Since only $\mathrm{N}-1$ injections are independent, there is a swing node (or "bus") that can be chosen arbitrarily as node N. $\underline{\mathrm{q}} \in R^{N-1}$ would then represent the truncated vector of net injections.

Power flow equations

$\widetilde{L}(\mathrm{z})=L(\underline{\mathrm{q}})=\underline{\mathrm{q}}^{t} \cdot \mathrm{B} \cdot \underline{\mathrm{q}}$

where $\mathrm{B} \in R^{N-1} \times R^{N-1}$ is a symmetric matrix.

$\mathrm{z}=\mathrm{H} \cdot \mathrm{q}$

where $\mathrm{H} \in R^{L} \times R^{N-1}$ is a "transfer admittance" matrix. Under the DC load approximation model, power flows are proportional to line's admittance $Y$, and the difference of phase angles $\delta$ at the extremities of the line, so that $z=Y \cdot \delta$. The line's admittance depends on its physical characteristics, and also determines the transfer admittance matrix (see Schweppe et al, 1988). (In practice, the transfer matrix could have thousands of rows and vectors, and it could be dense and hardly invertible. For these reasons, many practical implementations utilize the functional dependence of flows on phase angles).

\section{Transmission capacity constraints}

$\left|z_{l}\right|=\left|\sum_{n=1}^{N-1} H_{\mathrm{ln}} \cdot q_{n}\right| \leq K_{l} \quad \forall l=1, \ldots, L$

Physical limits on the line arise from thermal, voltage, and stability constraints. There are also operating limits. In an interconnected grid, power injections at all nodes potentially contribute to congestion.

The ISO's economic dispatch maximization problem is then to find an optimal vector $\left(\mathrm{q}^{* \mathrm{~s}}, \mathrm{q}^{* \mathrm{~d}}\right)$ that solves: 
(1) $\max _{q_{n}^{s}, q_{n}^{d}} \sum_{n=1}^{N}\left[C S_{n}\left(q_{n}^{d}\right)-C_{n}\left(q_{n}^{s}\right)\right]$

subject to

$$
\begin{aligned}
& \sum_{n=1}^{N} q_{n}^{s}=\sum_{n=1}^{N} q_{n}^{d}+\widetilde{L}(\underline{\mathrm{q}}) \\
& |\mathrm{H} \cdot \underline{\mathrm{q}}| \leq \mathrm{K}
\end{aligned}
$$

Locational prices are derived from the first order conditions of this program and defined as:

$$
\rho_{n}=\mu\left(1-\frac{\partial L}{\partial q_{n}}\right)-\sum_{l=1}^{L} H_{\mathrm{ln}} \lambda_{l}
$$

where $\mu$ is the Lagrange multiplier of the energy balance constraint, and $\lambda_{l}$ is the Lagrange multiplier of the transmission constraint on line $l$. Locational prices are therefore defined in terms of the shadow price of the constraints.

Optimal dispatch is then characterized (Schweppe et al, 1988) as:

$$
\rho_{n}=C_{n}^{\prime}\left(q_{n}^{s^{*}}\right)=C S^{\prime}\left(q_{n}^{d^{*}}\right)
$$

At the optimum, locational prices are such that consumers pay a marginal unit of power plus their marginal contribution to losses and to congestion of all lines in the network. Generators are paid their marginal unit of power, minus their contribution to losses and to congestion of all lines.

The economic dispatch model can be understood in the context of a static competitive equilibrium model (see Hogan, 2002b). The producing entity is an ISO that provides transmission services, receives and delivers power, and coordinates the spot market through solving program (1). On the consumer side, consumers inject power into the grid at some points and draw power out at other points.

\subsection{Nodal prices and financial transmission rights}

The difference in locational prices (2) defines the price for transmission usage for bilateral schedules. Hogan (1999a) emphasizes the "nodal" nature of locational prices because pricing by nodes is less complex in competitive markets. Hogan further argues that nodal prices provide the principles for economic dispatch and "are self policing and self auditing" (Hogan, 1999a, p.40), while zonal pricing implies deviations from reliable dispatch. For example, generators with a lower bid price than the zonal price ("constrained off" generators) that are located in nodes within the zone, have an incentive to selfschedule in bilateral contracts, thus compromising congestion management by the ISO.

Differences in nodal prices, congestion transmission charges and network congestion can vary widely over time. Demand and supply availability can also intertemporally vary. Variations in prices then create a demand by risk-averse agents for instruments to hedge against price fluctuations. A short-run financial transmission right (FTR) is such an 
instrument. Transmission congestion rents are redistributed by the ISO to market agents through FTRs (Hogan, 2002c).

Physical transmission rights are also discussed in the literature. However, tracing the physical flow through a transmission network has proven to be impossible in practice (Hogan, 2002c, p. 116; and Hogan, 2002a). Superiority of FTRs over physical rights has been analytically demonstrated as well (Joskow and Tirole, 2000).

Under an ISO's centralized structure, an FTR gives the holder a share of the congestion payment surplus that is received by the ISO when a transmission constraint is binding. The quantity of FTRs is fixed ex ante and allocated to holders to reflect estimates of the capacity of the network (Joskow and Tirole, 2002). The difference between actual transmission capacity and allocated FTRs results in congestion revenues for the ISO. For example, in the PJM system the revenues from FTRs are returned to owners of the transmission capacity so as to defray capital, operation and maintenance costs. The ISO defines the quantity of FTRs to be auctioned, and the auction rules. FTRs are defined in terms of the difference in nodal prices.

Hogan (2002a) discusses several financial transmission instruments such as rights, obligations and options. He argues that "point-to-point" (PTP) forward obligations have demonstrated to be the most feasible instrument in practice, which is not the case for PTP options and flowgate rights (flowgate rights are defined in terms of the selling of capacity constraint limits). PTP-FTR obligations can be either "balanced" or "unbalanced". A perfect hedge is achieved through a balanced PTP-FTR, while an unbalanced PTP-FTR obligation can be seen as a forward sale of energy.

Hogan (2002a) explains that the FTR market can be operated by the ISO in parallel with the spot market, as long as a simultaneous flow feasibility condition is met. A set of FTRs is simultaneously feasible if the associated set of net loads $q$ satisfies the energy balance and transmission capacity constraints, as well as the power flow equations. With many transmission lines and several possible contingencies, the number of constraints to be met in order to reach simultaneous feasibility can be in the hundreds of thousands. However, New York and PJM show that adequate software can be designed to solve this problem.

Likewise, Hogan (1992) shows that under a spot market equilibrium price $p^{*}$ and equilibrium load $q^{*}$, the "revenue adequacy" condition $p^{*}\left(q^{*}-q\right) \geq 0$ is met by a set of PTP-FTR forward obligations that are simultaneously feasible. Revenue adequacy is the financial counterpart of the physical concept of availability of transmission capacity (see Hogan, 2002b).

PTP-FTR forward obligations are usually allocated in auctions in which the ISO maximizes a concave and differentiable bid function $\beta_{k}\left(t_{k}^{f}, \rho_{k}^{f}\right)$ subject to simultaneous feasibility (where $t_{k}^{f}$ and $\rho_{k}^{f}$ are the scalar amounts of balanced and unbalanced FTR obligations, respectively). A solution to this problem determines the award of FTRs and the associated market clearing prices for awards, and it provides opportunities to reconfigure the pattern of FTRs.

The United States FERC and Mexican proposals foresee the use of locational marginal pricing, as well as congestion revenue contracts and tradable financial rights (see Federal Energy Regulatory Commission, 2002, pp. 116-148; and Secretaría de Energía, 2002, pp. 28-31). The PJM implementation of FTRs employs a DC-load dispatch model where locational prices differ due to the effects of congestion. PTP-FTRs are then defined for 
congestion-cost payments. In New York, losses are included in the dispatch model and only balanced PTP-FTRs are defined to provide payments for congestion costs but not for losses. An AC formulation is used to define the FTR auction.

The experience of PJM, New York, and recently the New England market shows that FTRs can be traded in secondary markets. The liquidity of such markets is supported by the formal dispatch process carried out by the ISO so that FTR secondary markets are imbedded. Although it may be true that an FTR does not always exist between two points for large nodal systems, whenever there is a need for an FTR between any two nodes, it is always possible to derive it from nodal price differences during the FTR auction dispatch process. Market experience has also demonstrated that FTRs can be traded in almost every intertemporal framework ranging from years to months and even weeks (transactions of less than one week are not relevant).

\subsection{Long-term FTRs and transmission expansion}

We now turn our analysis to the forward transmission market. We explore how to reach an equilibrium in this market building on the spot market equilibrium, as illustrated by the economic dispatch model. Specifically, we are interested in studying optimal mechanisms to attract investment for the long-term expansion of the transmission network. There are three approaches that - building on equilibrium in the spot market - utilize long-term mechanisms such as FTR auctions, price caps, and market-power analysis in order to provide investment incentives. We analyze in the remaining part of Section 3 the use of FTRs to solve the transmission investment problem, while in Sections 4 and 5 we study the other alternative approaches.

The power flow model provides nodal prices through the shadow prices of the model's constraints. FTRs are derived from such shadow prices. However, short-term FTRs alone cannot resolve the problem of incentives for long-term transmission expansion. The approach of using FTRs to address the problem of long-term (LT) transmission expansion relies on a centralized ISO that allocates through an auction the necessary LT FTRs to protect the holders from future unexpected changes in congestion costs. LT transmission rights work in parallel with LT generation contracts (see Hogan, 2002b, p. 17). The LT concept is important for expansion projects. As argued by Gribik et al (2002), most auctions allocate FTRs with durations of one month through five years. Since a transmission project has a useful life of approximately 30 years, the owner of such a project would prefer to receive LT FTRs.

Typically, the LT FTR allocation mechanism relies on the operation of a short-run spot market for energy and ancillary services by the ISO, and on a bid-based, securityconstrained, economic dispatch with nodal pricing. Authors in this area (Hogan, 2002b) see the LT FTR alternative as a merchant transmission investment because incremental FTRs can provide market-based transmission pricing that attracts transmission investment.

Bushnell and Stoft (1997) argue that market failures in electricity transmission are due to several factors: a) the market power of a single owner of the transmission capabilities in a region; b) the external benefits of transmission investments that are not appropriable; and c) the negative externalities caused by investment in a specific transmission link over the transmission capacity of other links. Expanding on this last externality, Bushnell and Stoft studied the effects of transmission expansion in a three-node network. They showed that expansion investment might violate some of the existing property rights, and proposed to 
require the agent willing to make the expansion to "pay back" for the possible loss of the property rights of other agents.

Bushnell and Stoft use an example of a network with loop flow. Given an initially radial three-node configuration with two links, they consider the effects of adding a third line. The new link creates a new feasible set that requires a redispatch of the net loads at each node. Loads (and associated FTRs) that were not previously feasible (pre-investment) became feasible (post-investment), while pairs of loads (and associated FTRs) that were feasible became infeasible. In particular, the initial optimal dispatch is no longer feasible, and the expansion link reduces social welfare because it is a binding constraint on low-cost generation schedules. (Implicitly, Bushnell and Stoft's model relies on the assumption of agents that operate in a spot market but do not hold LT FTRs so that the externalities are due to lack of hedging by spot market participants). The new link is therefore inefficient and should not be built. However, one way to proceed with the line expansion is to make the investor pay for the negative externalities that are generated. Thus, to restore feasibility, the investor must buy back sufficient rights from initial holders.

Bushnell and Stoft (1997) further demonstrate that the value of newly allocated FTRs dispatched according to the feasibility rule will be less than or equal to the change in social welfare. In particular, if social welfare is decreased by a transmission expansion, the investor will have to take FTRs with a negative value (there will be free riding if social welfare is increased). Some agents might still benefit from investments that reduce social welfare, whenever their own commercial interests improve to an extent that more than offsets the negative value of the new FTRs. This problem can be solved if it is required that FTRs are used by each agent as a perfect hedge for their net load. In such a case, FTRs allocated under the feasibility rule ensure that no one will benefit from an expansion that reduces welfare.

Hogan (2002b) generalizes Bushnell and Stoft's analysis and makes a preliminary attempt to analytically provide some axioms to properly define LT FTRs. Hogan's model relies on an institutional structure in which various established agents (generators, Gridcos, marketers, etc.) are interested in the expansion of the transmission grid, as opposed to a single owner of the grid. Under an initial condition of incomplete allocation of FTRs, the awarding of incremental LT FTRs (say 20 years) should satisfy some basic criteria.

The first criterion is that an FTR increment is always simultaneously feasible (feasibility rule) (recall that a set of FTRs is simultaneously feasible if the associated net power flows are also simultaneously feasible). The second is that such an increment remains simultaneously feasible given that certain currently unallocated rights (or proxy awards) $\hat{T}$ are preserved. In other words, the transmission energy balance and capacity constraints, as well as the power flow equations, are satisfied for $\hat{T}+T+\delta$ (where $T$ is existing rights, and $\delta$ is incremental rights). The third criterion is that investors maximize their objective function (maximum value); the fourth implies that the awarding process applies both for decreases and increases in grid capacity (symmetry).

Under these conditions, the allocation of new PTP-FTR obligations will not reduce social welfare (Bushnell and Stoft, 1996, and Bushnell and Stoft, 1997). Hogan explains however, that defining proxy awards is a difficult task. One possibility would be to define every possible use of the current grid as a proxy award. This rule would not be a good idea in practice because it precludes any investment beyond a radial line (a network with only two nodes and one transmission line). Any incremental award of FTRs might require adding capacity to every link on every path of a meshed network. 
Hogan adds that it would be better to define as a proxy award the best use of the current grid along the same direction that the (positive or negative) incremental FTR was awarded. The main problem then is how to define best use. One way is to define "best" in terms of preset proxy references so that proxy awards maximize the value of such references. Another possibility is to define "best" in terms of the maximum value of investors' preferences. Proxy awards would then minimize such maximum value.

Given a proxy rule, an auction could be carried out in order to attract investment for transmission expansion. In case the investor's preference criterion is chosen, the auction model would maximize the investor's preferences to award $\theta$ MWs of FTRs in direction of the expansion $\delta$, subject to the simultaneously feasibility conditions and the "best" rule.

\subsection{Practical proposals}

Pope (2002) makes a more detailed attempt to implement an LT FTR mechanism. By designing an auction process for incremental FTRs (or Transmission Congestion Contracts as in the New York ISO) associated with transmission expansion that provides a hedge against congestion costs in both the short and long terms. The ISO awards incremental FTRs to the parties that fund the expansion, only if the new FTRs are made possible by such an expansion. FTR awards are mainly based on choices made by investors although the ISO could identify incremental FTRs in certain cases.

When investors choose an increment in FTRs for transmission expansion, simultaneous feasibility of both the already existing FTRs (including "grandfathered" FTRs, and FTRs purchased in auctions) and the new FTRs must be checked, since the amount of power that could be transferred between many different pairs of nodes (or buses) could be affected by the expansion. The auction process also controls investors' nominations to preserve simultaneous feasibility, and excludes granting already existing FTRs that were not made possible by the expansion. When defining expansion FTRs, the ISO will also temporarily reserve some feasible FTRs prior to the expansion.

Pope's bidding process consists of several steps. Given pre-existing FTRs, in the first step, investors are offered the choice between long-term and short-term (ST) expansion FTRs (LT FTR awards are one-time awards for a 20 -year period, while ST FTR awards occur every six months). In a second step, allocation of new expansion LT FTRs takes place in either an auctioned period or an unauctioned period. In the auctioned periods, the FTR auction model is used to sequentially determine incremental expansion awards. Investors nominate expansion FTRs (either in winter or summer), and assign to each one a certain positive valued weight that indicates preference for each FTR. (Differentiation of "winter" FTRs from "summer" FTRs is not trivial since an incremental FTR that is feasible in one period might be infeasible in another.) This model maximizes investors' preferences, and is simultaneously feasible with all pre-expansion FTRs. "Mitigating" counter flow FTRs with negative expected value and weights are also assigned to preserve the feasibility of pre-expansion FTRs as well as to give rise to more valuable FTRs. In the unauctioned periods, another mechanism is designed to reserve capacity for sales in later auctions, rather than leave all the available capacity for expansion awards. In a third step, the auction and allocation of ST FTRs occurs.

Harvey (2002) provides a preliminary analysis of incremental-expansion LT FTR awards for controllable lines such as DC lines. For a controllable line, he analyzes the pricing of energy, the method for representing the line in FTR feasibility tests, and the method to determine the quantity of supportable (and feasible) FTRs. Such analysis 
depends on whether a controllable line is proposed by a market agent or by the ISO. For example, if a market participant schedules the line, pricing of the line might differ from locational marginal pricing when the outage of the controllable line is a binding constraint. Meanwhile, locational marginal pricing would operate if the ISO controls and schedules the lines.

Another alternative effort to define LT rights is provided by Gribik et al (2002). They base their method on the physical characteristics of the transmission network - namely capacity and admittance - in contrast to the definition of incremental PTP FTRs that, as shown by Hogan (2002b), Pope (2002), and Harvey (2002) can give rise to numerous inconsistencies.

Gribik et al confirm that allocation of PTP FTRs associated with transmission expansion mainly depend on PTP FTRs allocated prior to the expansion. Flowgate rights allocated to owners of a transmission expansion might not reflect the value of the additional transmission capacity. Hence, they propose a method to allocate flowgate rights for the new capacity added by the owner of an expansion, as well as admittance rights to collect the marginal value of access to the added facility.

As in all LT FTR models, their DC power flow model assumes a centralized ISO that auctions PTP FTRs and collects revenues from the sales of FTRs in the auction. The revenues are used to make payments to owners of transmission facilities. The ISO calculates in the auction two main components of the LT fixed costs associated with transmission expansion: the shadow price (or marginal value) of the capacity of the line, and the shadow price of the admittance to the line. The ISO then pays the owners according to a two-part tariff: a capacity payment (shadow price of capacity times the capacity of the line), and an admittance payment (shadow price of admittance times the admittance of the line).

The auction model assumes that some previous PTP FTRs were allocated. As in Pope (2002), with the new FTRs associated with expansion, the resulting power flows should remain simultaneously feasible. Gribik et al define the power flow equations, energy balance and transmission capacity constraints before and after the new line is added. When the new line is added, it might be possible that the original set of FTRs is no longer simultaneously feasible. In that case, the owner of the expansion is required to add (or buy back) enough FTRs so that the resulting set of FTRs satisfies the simultaneous feasibility test.

In the FTR auction for the expanded system, the ISO maximizes the value of FTRs subject to ex post (after the new line is added) power flow, energy balance and transmission capacity constraints. Gribik et al confirm for their model that a PTP FTR obligation will depend on the difference in nodal prices. They also calculate the total payment (admittance plus capacity payments) paid by the ISO from the FTR as well as check the revenue adequacy of their mechanism (Gribik et al, 2002, appendix A). They also show with an example that negative payments are possible when the direction of the change in power flow is from a node with higher nodal price to a node with lower price. These negative payments indicate the need for equipment (such as phase shifters) to control power flows and, hence, to eliminate negative payments.

\subsection{Discussion on LT FTR mechanisms}

Practical implementation of any of the above-described LT FTR mechanisms requires more than analytical and computational developments. Hogan (2002b) argues that practical 
implementation of his proposed auction has to consider incentives for merchant transmission investment, as well as the software needed to solve such a problem. Most importantly, the question is whether such an auction mechanism could produce in practice acceptable proxy awards and incremental FTR awards. Hogan's examples show how simple expansions in a three-node network might have complex implications for the grid. Assuming LT rights that do not use the full capacity of the grid and proxy awards that use the rest of the capacity, an investment that introduces a different link in the network will change impedances (resistances) and flows to the network, both expanding and contracting the set of feasible FTRs (Hogan, 2002b, p. 15).

Likewise, even though Gribik et al (2002) present a novel idea based on an explicit pay for admittance, these payments are really a transfer of rents among transmission owners, which raise questions about the strategic behavior of investors. It can be observed that the revenue-balance problem in their model is solved through the payment of all admittance costs but for only part of the capacity that is defined as incremental. This solution might fall short from supporting efficient expansion whenever revenues are not able to justify total capacity costs.

Additionally, various authors coincide in the need to mitigate market power for any FTR auction to work. As shown in the literature (Joskow and Tirole, 2000; Léautier, 2001; Gilbert, Neuhoff, and Newbery, 2002) ownership of FTRs can exacerbate market power in generation. Joskow and Tirole (2000) study a two-node export-import network under several scenarios of market structure both in the generation market and the FTR market. They show that market power in the FTR market by a producer in the importing region (or a consumer in the exporting region) aggravates their monopoly (monopsony) power, since dominance in the FTR market provides an incentive to curtail output (demand) to make FTRs more valuable.

Generators' behavior in the FTR market should then be regulated. In fact, Hogan (2002b) believes that transmission companies should be the principal buyers and sellers of LT FTRs. In particular, Gridcos could have the primary responsibility of making a regulated investment under market failure conditions, but this also requires strict enforcement for open access to transmission networks.

In addition, Joskow and Tirole (2002) and Joskow and Tirole (2003) offer a more extensive critique of the short-run version of the FTR model and its ability to provide proper incentives for transmission investment. They argue that the FTR model relies on strong assumptions of perfect competition that permits efficiency results (such strong assumptions include: no increasing returns to scales; no sunk costs; nodal prices that fully reflect consumers' willingness to pay; network externalities internalized by nodal prices; no uncertainty over congestion rents; no market power so that markets are always cleared by prices; a full set of future markets; and an ISO with no internal intertemporal preferences regarding effective transmission capacity). Under these assumptions, the FTR solution allows investment in transmission to compete with investment in generation and solves the natural monopoly regulatory problem (see Joskow and Tirole, 2002, p. 15). However, when such assumptions are lifted, the nice results of the model are no longer valid and FTRs do not fully provide enough incentives to avoid transmission congestion. For example, under a pay-as-bid pool rule Léautier (2000) shows that even under FTR payments, monopoly generators have incentives to reduce transmission capacity in order to preserve local market power. Bushnell (1999) and Joskow and Tirole (2000) reach a 
similar conclusion for physical transmission rights since they can be withheld, thus reducing transmission capacity.

Joskow and Tirole also point out that since most electricity markets are volatile in nature (Borenstein, 2002, argues that market power and volatility are inherent to electricity markets since demand is difficult to forecast and is inelastic) no restructured electricity sector in the world has adopted a pure merchant approach towards transmission expansion. As previously discussed, the PJM and NYISO regimes apply a LT FTR approach under a centralized ISO. Australia is an interesting case where a mixture of regulated and merchant approaches has been recently implemented (see Littlechild, 2003, for an evaluation of the Australian regime for transmission expansion). Argentina also relies on a combined regulatory-merchant approach, while New Zealand is in the process of designing its regime (both countries have ISO regimes with nodal pricing).

Joskow and Tirole then carry out an extensive analysis on the implications of lifting these strong assumptions. First, Joskow and Tirole (2003) argue that due to market power in constrained regions, prices will not reflect the marginal cost of production. Generators in constrained regions will tend to withdraw capacity to bring their generation price up, and this will overestimate the cost-saving gains from investments in transmission. Second, lumpiness in transmission investment implies that the total value paid to investors through FTRs understates the social surplus created by such an investment. The large and lumpy nature of major transmission upgrades then needs LT contracts before making the investments, or property rights (or "patents") to exclusively use the incremental investment for a certain period.

Third, since transmission investment is not static in reality, there is no perfect coordination of interdependent investments in generation and transmission. In fact, the stochastic changes in supply and demand conditions imply uncertain nodal prices. Fourth, equal access to investment opportunities is not a good assumption because deepening investments of the incumbent's network can be efficiently implemented only by the incumbent. Fifth, existing transmission capacity and incremental capacity are not well defined and are of a stochastic nature. Even in the two-node case, realized capacity could be less than expected capacity so that the revenue-adequacy condition is not met. Sixth, the separation of transmission ownership and system operation creates a moral-hazard "in teams" problem. For example, an outage can be claimed to result from poor line maintenance (by the transmission owner) or from imprudent dispatch (by the ISO). Seventh, as shown by Bushnell and Stoft for a network with loop flow, an addition in transmission capacity might have a negative social value. Additionally, the initially feasible FTR set can depend on random exogenous variables.

Hogan responds to Joskow and Tirole's criticisms to the FTR approach. Hogan (2002b) analyzes the implications of loop flows on transmission investment raised by Bushnell and Stoft (1997). As discussed in Section 3.3, Hogan (2002b) analytically provides the general axioms needed to define LT FTRs properly so as to deal with negative externalities implied by loop flows.

Hogan (2003) agrees that LT FTRs only grant efficient outcomes under lack of market power and non-lumpy marginal expansions of the transmission network. He thinks that regulation has an important role in fostering large and lumpy projects, and in mitigating market power abuses.

As argued by Pérez-Arriaga et al (1995), revenues from nodal prices only recover $25 \%$ of total costs. LT FTRs should then be complemented with a fix-price structure or, as in 
Rubio-Odériz and Pérez-Arriaga (2000), a complementary charge that allows the recovery of fixed costs. In the United States, transmission fixed costs are recovered through a fixed charge regulated through cost-of-service regulation, even in systems that are based on nodal pricing and FTRs. The need for regulation is recognized by Hogan (1999b) who believes that complete reliance on market incentives for transmission investment is undesirable. Rather, Hogan (2003) thinks that merchant and regulated transmission investments could be combined so that regulated transmission investment is limited to projects where investment is large relative to market size, and lumpy so that it only makes sense as a single project as opposed to many incremental small projects. The problem is then how to define a workable boundary between merchant and regulated investments in practice.

Hogan also responds to contingency concerns (Hogan, 2002a; Hogan, 2002b; Hogan, 2003). On one hand, only contingencies outside the system operator's control could lead to revenue inadequacy of FTRs, but such cases are rare and do not represent the most important contingency conditions. On the other hand, most of remaining contingencies are foreseen in a security-constrained dispatch of a meshed network with loops and parallel paths. If one of " $n$ " transmission facilities is lost, the remaining power flows would still be feasible in an "n-1" contingency constrained dispatch.

Hogan (2003) also accepts that agency problems and information asymmetries are part of an institutional structure of the electricity industry where the ISO is separated from transmission ownership and where market players are decentralized. However, he thinks that the main issue for transmission investment is the boundary between merchant and regulated expansion projects. It is not clear how asymmetric information might affect such a boundary.

Further, Harvard Electricity Policy Group (2002a) recognizes that workable rules are needed to avoid free riding under the considerable economies of scale and scope of grid investments. Demand and generation side solutions that reduce congestion should also be taken into account. But maybe, the major consensus in the FTR literature is the unavoidable (and paradoxical) coexistence of central planning and merchant investment needed for the LT forward transmission market to work, and to attract the necessary investment for expanding the system. Central planning must accompany merchant investment due to the economies of scale, and the free riding and congestion incentives, present in a transmission expansion investment process. As Joskow and Tirole (2002) argue, "the merchant transmission model cannot operate as by an invisible hand" since that model requires a centralized ISO. These authors then call for a careful definition of the role of the ISO in planning opportunities, timing, and degree of participation in transmission expansion. Their view is supported by FERC's SMD that promotes the use of a regional planning process to guide investments in transmission infrastructure (see Federal Energy Regulatory Commission, 2002, pp. 193-201).

However, a question remains on how a central planned system would accommodate transmission investments in unplanned expansion projects, considering their impact on social welfare. This issue seems to be very complex since the impact that a new transmission line might have on the value of existing lines depends on the specific future uses of the network. This means that such effects depend on the probabilities of all states of the world over an entire investment horizon. Since these probabilities are of no common knowledge, the actual probabilities chosen by the ISO could be rather subjective. Likewise, markets for such contingencies could hardly be implemented in practice because 
this presupposes that the owners of the existing network would not be neutral with respect to new investments. Hogan (2002a) argues that contingencies in the short-run FTR model can be addressed through security-constrained economic dispatch. Beyond the computational difficulties for the ISO of calculating the probabilities of contingencies, it remains to be seen if the $\mathrm{LT} \mathrm{FTR} /$ merchant approach can really solve the loop flow problem.

Another interesting feature of the LT FTR model is that it fails to consider the transmission activity as an output (or throughput) process. The reason being the impossibility to follow any physical trace of the volume transmitted through the electricity wires. Although this is, of course, true in practice, there is at least the analytical question on the way cost and production functions in electricity transmission behave. If, as in other infrastructure industries (such as the gas industry), electricity transmission presents large sunk costs and cost subadditivity, then why not think about how to regulate the long-term monopolistic behavior of a Gridco through some type of incentive regulation? We address this issue in the next Section.

\section{$4 \quad$ Incentives for transmission expansion through regulatory mechanisms}

A totally different approach towards transmission expansion is provided by a body of literature on the design of economic regulatory mechanisms for Transcos (Léautier, 2000; Grande and Wangesteen 2000; Vogelsang, 2001; Joskow and Tirole, 2002). An incentivecompatible regulatory mechanism for a Transco must provide incentives to the regulated firm to make efficient investment decisions, and must also permit the regulated firm to earn enough revenues to cover capital and operating costs in an imperfect information environment about cost and demand functions.

\subsection{Regulation of a Transco}

Building on a power flow model, Léautier (2000), Grande and Wangesteen (2000), and Harvard Electricity Policy Group (2002a, pp. 27-32) propose mechanisms that compare a Transco's performance with a measure of welfare loss due to its activities. The Transco is then penalized for increasing congestion costs in the network. In Léautier (2000), the regulator offers the regulated firm a menu of contracts that, according to the revelation principle (as in Laffont, 1994; Laffont and Tirole, 1993), induces the firm to operate and build transmission lines efficiently while still permitting it to recover its costs. Under the mechanism, the firm is responsible for the costs of congestion it creates and the needed investment to relieve it. The Transco has an incentive to minimize congestion, while a separate mechanism provides incentives to invest in the optimal amount of transmission investment.

More specifically, Léautier (2000) shows that a marginal increase in transmission capacity has two effects: a direct effect so that cheap power substitutes for expensive power, and an indirect effect that reflects the results on other transmission lines due to the expansion. The author defines the cost of congestion as the difference between the price actually paid to generators and the price that would have been paid absent congestion. Such a difference is called the "out-turn." Additionally to the Laffont-Tirole menu of revenue sharing rules, Léautier defines an "uplift management rule" that makes the Transco responsible for the full cost of the out-turn, plus any transmission losses. This 
mechanism has been applied in England and Wales, where transmission pricing is typically separated from energy pricing.

Joskow and Tirole (2002) propose a simple surplus-based mechanism to provide the Transco with enough incentives to expand the transmission network. The idea is to reward the Transco according to the redispatch costs avoided by the expansion, so that the Transco faces the entire social cost of congestion. Joskow and Tirole argue that such a mechanism will eliminate the problems associated with lumpiness and loop flows. The specification and allocation of FTRs would not be a problem, and operation and ownership of the transmission network could be joint because the moral-hazard-in-teams problem is eliminated.

As an alternative, Vogelsang (2001) explicitly studies the nature of the cost and production functions for electricity transmission. Since electricity transmission generally preserves its technological characteristics of natural monopoly, this approach attempts to isolate the monopolistic nature of a for-profit Transco that owns the complete transmission network, and designs an incentive regulatory scheme to regulate it. Although Vogelsang's mechanism is designed to be implemented under the Transco institutional framework, it could also be combined with a (centralized) ISO that takes care of the short-run market, and an independent transmission company that handles investment issues.

Regulation of transmission must then solve the duality of incentives for the transmission firm in both the short term and the long term since under a non-adequate tariff scheme the firm could find it profitable not to solve congestion problems by investing in network expansion. Conditions for optimal capacity expansion have been studied by the peak-load pricing literature: the per-unit marginal cost of new capacity must be equal to the expected congestion cost of not adding an additional unit of capacity. However, the question remains how regulation can provide incentives to reach this point

\subsection{Price level and price structure regulation for a Transco}

Applied price-cap mechanisms can be analyzed from two perspectives: regulation of "price level" and regulation of "price structure" (see Brown, Einhorn, and Vogelsang, 1991). Price level regulation refers to the long-run distribution of rents and risks between consumers and the regulated firm. Price structure regulation refers to the short-run allocation of costs and benefits among distinct types of consumers. There are several options to regulate for price level (such as cost-of-service, price-cap, and yardstick regulations) as well as for price structure (such as price bands or flexible price structures). (See Vogelsang, 1999).

Vogelsang (1999) believes that price cap regulation (together with typical inflation $(R P I)$ and efficiency factors $(X)$, and cost-of-service reassessment every five years) is the best price-level regulatory option for electricity transmission tariffs. Since transmission costs are so dependent on geographic localization, the construction of an adequate cost or price benchmark would not be feasible, and pure cost-of-service would be too cumbersome to implement.

However, price structure regulation can be used to solve transmission congestion, in the short run, as well as capital costs and investment issues in the long run. Vogelsang (2001) proposes a two-part tariff regulatory model with variable (or usage) charges, and fixed (or capacity) charges (Hunt, 2002, p. 196-201, discusses the practical hurdles to defining such charges). The variable charge can also be understood as a nodal price in the sense of the FTR literature (see Vogelsang, 2001, p. 143). The Transco is a profit- 
maximizing monopolist that makes investment and pricing decisions subject to regulation of its two-part tariff. In the radial line case, the solution of this problem relieves congestion problems through the variable charges. Recuperation of long-term capital costs is achieved through the fixed charge, while incentives for investment in expansion of the network are reached by rebalancing the fixed and variable charges. Transmitted volumes for each type of service are used as weights for the corresponding different prices so that the Transco's profits increase as capacity utilization and network expansion increase. In equilibrium, rebalancing of fixed and variable charges depends on the ratio between the output weight and the number of consumers.

Broadly speaking, Vogelsang's mechanism works as follows: in times of excess capacity, the variable charge of the two-part tariff decreases, causing an increase in consumption. The fixed charge, in turn, augments so that total income increases despite the diminishment of the variable charge. As a consequence, the Transco does not invest more in capacity expansion and net profits grow since costs do not augment. On the contrary, when there is congestion in capacity, the variable charge will be a pure congestion charge and, if congestion charges are in the margin greater than the marginal costs of expanding capacity, the Transco will have incentives to invest in new capacity. This regulatory mechanism is shown to be superior (in welfare terms) to a linear price cap (Vogelsang, 2001, p. 147) and to an average-revenue constraint as the one discussed by Sappington and Sibley (1992).

Under fluctuating and inelastic demand, Vogelsang extends the two-part tariff pricecap approach to permit time-fluctuating prices. Under a radial transmission line, and assuming a long-run cost function, he defines time-specific or location-specific services that are repeated each period. Many small subperiods share the same capacity constraint so that in off-peak subperiods the marginal cost is zero, while in peak subperiods the marginal cost is positive. All subperiods are further assigned to a single common weight, which implies an average-revenue constraint as described by Ramirez and Rosellón (2002). The use of this constraint produces first-order conditions different from the optimal conditions since the average revenue constraint is softer than the Laspeyres one (see Bradley and Price, 1991; Sappington and Sibley, 1992). Vogelsang therefore proposes additional constraints to the price cap, including market rules that assure competitive spot prices and weights restricted to peak quantities. These conditions ensure lower prices and more investment over time.

In the fluctuating demand case, Vogelsang (2001) proposes defining fixed fees heterogeneously. The fixed fee really pays for access and usage so that the two-part tariff may actually consist of two linear prices for two services. There are three alternatives for the unit of consumption of the now "variable" fixed fee. First, fixed fees might pay for total capacity. Second, the quantity used to calculate the fixed fee is defined by peak capacity. Third, the fixed fee could be allowed to grow according to a predicted rate.

\subsection{Discussion on regulatory mechanisms}

Regulatory mechanisms for transmission expansion also face implementation hurdles. For example, Joskow and Tirole (2003) recognize that their scheme might not work whenever the Transco is vertically integrated with generation so that the integrated company manipulates bids in the energy market. Even with no vertical integration, generators might invest no more than what is needed to match existing transmission capacity. 
Regarding price-cap mechanisms, probably the main virtue of Vogelsang's approach is that it tries to deepen the analysis of the cost and demand functions for transmission services, which are very poorly understood by the current economics literature. The costs of a Transco are generally sunk, therefore the problem is short-run utilization of capacity. The main variable costs are associated with congestion. In the long run, however, the Transco finds an optimum between network expansion and investment-cost minimization through the rebalancing of fixed and variable fees.

In Vogelsang's model, incentives for investment crucially depend on the type of weights used. For each service, a Laspeyres index uses the quantity of the previous period as weight for the price. When this type of weight is used, the Transco will not immediately invest the total difference between current capacity and optimal capacity since it faces a tension between gains from congestion or increases in the capacity charge. The Transco does not immediately equate the marginal income from investing (given by consumers' willingness to pay) with the marginal cost of investment. However, investment will continue through time until it converges to the optimal level, and transmission tariffs, in turn, will converge to Ramsey prices. This is because profit will increase over time less than welfare over time (using previous period outputs forces decreases in prices, therefore, increases welfare. See Vogelsang, 2001, p. 148).

These results are true only if it is assumed that cost and demand functions are stable, and that the Transco does not use strategic conduct in setting its prices (see Vogelsang, 1999, pp. 28-31). In the case of changing cost and demand functions, or non myopic profit maximization, convergence to Ramsey prices under the Laspeyres index cannot be guaranteed (see Fraser, 1995; and Neu, 1993). To overcome such a problem, Vogelsang proposes the use of the mean of Laspeyres and Paasche (current quantity) indexes. He shows that in a two-period framework, and under a concave behavior of demand, this option performs better (in terms of welfare) than Laspeyres weights. However, in a multiperiod framework, the mechanism may diverge from marginal cost since it could be subject to strategic behavior of the Transco. This last result is very similar to the ones in Sappington and Sibley (1992), and Ramírez and Rosellón (2002).

The major criticism to Vogelsang's price-cap approach is that its simplifying assumptions make the possibility of its application doubtful. First, in order to develop a proof of convergence to the Ramsey optimal outcome, Vogelsang (2001) assumes that the transmission demand functions are differentiable and downward sloping, and that transmission marginal costs curves cut demands only once. As shown in Hogan (2002b), this assumption is generally invalid since, under loop flows, an expansion in a certain transmission link can result in a total decrease of the network capacity. Second, to study the cost and production characteristics of a Transco, Vogelsang finds it useful to define the Transco's output (or throughput). As argued in the FTR literature (Bushnell and Stoft, 1997; Hogan, 2002a; Hogan, 2002c), this task is difficult since the physical flow through a meshed transmission network cannot be traced. Third, Vogelsang abstracts from the existing substitution relationship between transmission and generation projects (while the FTR model folds transmission price to generation bids).

These objections do not mean that the Vogelsang's mechanism fails in the presence of loop flows, but merely that its behavior under loop flows has not yet been analyzed in the literature. In a network with loop flows, outputs under the price-cap approach could be defined as bilateral trades between pairs of nodes that aggregate to net injections at all nodes. Additionally, as argued by Hunt (2002), since transmission investment in the long 
run is subject to uncertainty the regulated Transco approach appears to have an advantage over the FTR/merchant approach because the Transco makes all externality calculations and associated probability assessments by itself. In other words, the Transco itself solves the loop flow problem, and regulation through a price-cap scheme provides a costminimizing outcome.

Rosellón (2003) attempts a preliminary application of the Vogelsang mechanism to the electricity transmission system in Mexico, for the case of a stable demand growth for electricity. He analyzes three scenarios: (i) a single Transco that offers transmission service nationally and applies postage-stamp tariffs to all consumers; (ii) several regional companies that independently operate in each of the nine areas of the national transmission system, and charge different tariffs; and (iii) a single Transco that operates in all the areas of the national transmission system but differentiates the prices applied in each region. Achieved investment and profits are highest under the first scenario. A further step would entail more empirical research to understand the problems of implementing a price-cap approach for transmission expansion. Analyzing such problems could explain why other developed electricity industries use a revenue-cap approach (see Jordanger and Grønli, 2000, for the case of Norway). A revenue approach might preclude having to exactly define the output produced by a Transco.

Vogelsang (2001) argues that the price-cap mechanism could also be applied under the (centralized) ISO approach. The ISO would run the short-term utilization of the transmission system (through a bid-based, security constrained market, together with locational marginal pricing), while the Gridco would own and physically operate the transmission network and collect congestion charges and fixed fees. However, the ISO would need a well-defined objective function, a task that also seems difficult to be solved in practice. Variables that might influence the ISO's objective function could include the total amount traded over the transmission system and the average nodal price difference.

The crucial issue in a transmission grid relies on the comparison of the congestion gains and the gains for the expansion of the network. The LT FTR model provides efficient results whenever congestion gains are not larger than the benefits from expansion. In such a case, there would be incentives to expand the grid. In the opposite case, when it is more profitable for the transmission company to keep a congested network than to expand it, even a small expansion will have such an impact on tariffs that there would be no incentive to expand the grid.

The relationship between market power and transmission expansion is of much interest. Under what conditions does transmission expansion mitigate or exacerbate market power? How does market structure in the generation market determine the transmission expansion projects? How does market power in the FTR market affect market behavior in generation and electricity consumption? We study the literature that addresses these matters in the following Section.

\section{Transmission expansion and market power}

Léautier (2001) studies the effects of an increase in transmission capacity in a three-node network model of two periods. In the first period, transmission expansion takes place, so that the owner of the transmission assets receives revenues. In the second period, the SO carries on dispatch in order to maximize consumer surplus and according to a pay-as-bid 
function. The model allows for loop flows. He finds two main effects. First, a substitution effect: transmission expansion permits that cheaper power substitutes for more expensive power. Second, a strategic effect: competition in generation increases. The substitution effect is always welfare improving, but the net welfare outcome of the strategic effect depends on the weight of generators' profits relative to the consumers' utility weight. The higher the generators' weight, the lower the positive effect on welfare.

Therefore, Léautier argues that incumbent generators may not always be the best economic agents to carry out transmission expansion projects. Although such expansions allow generators to enhance the revenues gained by improved access to new markets and increased transmission charges and FTRs, the gains could be overcome by the loss of local market power. Thus, in general, generators might prefer to congest transmission lines (see Léautier, 2001, pp. 44-47). The regulator must then take measures to vertically separate the electricity industry, so that expansion projects may be undertaken by any economic agent.

\subsection{Market power and the FTR market}

The FTR literature reveals that the expansion of the transmission network has an impact on the market power of other electricity industry agents, such as generators and consumers. As shown in an extensive body of literature, generators can more easily exert local power when the transmission network is congested (see Bushnell, 1999; Bushnell and Stoft, 1997; Joskow and Tirole, 2000; Oren, 1997; Joskow and Schmalensee, 1983; Chao and Peck, 1997; Gilbert, Neuhoff, and Newbury, 2002; Cardell, Hitt, and Hogan, 1997; Borenstein, Bushnell and Stoft, 1998; Wolfram, 1998; Bushnell and Wolack, 1999). Specifically, Bushnell and Stoft (1997) show that in a three-node network, a single generator might benefit from a welfare-inefficient expansion, while Joskow and Tirole (2000) study various market structure scenarios in the generation and FTR markets. They find that a predominant position in the FTR market by a monopoly generator increases its monopoly power, since such dominance provides incentives to cut generation so as to make FTRs more valuable.

The precise allocation of FTRs under a monopoly generator depends on the (micro) structure of the FTR market (Joskow and Tirole, 2000). When a single owner who is neither a generator nor a consumer initially holds all FTRs, the monopoly generator will want to acquire all FTRs. When the initial ownership of FTRs is dispersed among economic agents without market power, the generator will buy no FTR. When the FTRs are auctioned to the highest bidders, the generator will purchase a random number of FTRs. Building on this analysis, Gilbert, Neuhoff, and Newbury (2002) study ways to cancel perverse incentives by identifying conditions where different allocation processes of FTRs can mitigate generation market power when transmission capacity is constrained. For example, in an arbitraged uniform price auction, generators will purchase FTRs that mitigate their market power, but in a pay-as-bid auction FTRs might enhance the generator's market power. When the generator is not allowed to own FTRs that are not related to its own energy delivery, market power might be mitigated in a two-node case. However, in the three (or more) node case, mitigation of market power implies defining FTRs according to the reference node with the price least influenced by the generator's output decision.

In practice, market power mitigation mechanisms are generally included in any electricity reform proposal based on the FTR model. Mexico's reform proposal foresees that the Mexican Energy Regulatory Commission will establish the necessary regulations 
for generators with market power (Secretaría de Energía, 2002, Section 5.4). Comisión Federal de Electricidad (2000) demonstrates that the isolated peninsular and northwest regions are more susceptible to market power abuse than central regions. In the United States, FERC's recent reform proposal contains specific sections on "market power mitigation" (see Federal Energy Regulatory Commission, 2002, pp. 224-259). FERC's SMD identifies insufficient demand-side response and the existence of transmission constraints as the two principal causes for the presence of market power in electricity markets. FERC also differentiates high prices due to scarcity and high prices resulting from exercising market power. Building on a merit-order spot market mechanism, it proposes to use a bid cap for generators with market power in a load pocket, and a "safety net" ( markets) for demand-side response. Regulated generators are also subject to a resource adequacy requirement. Chandley and Hogan (2002) believe that this last mechanism is inefficient because the use of penalties for undercontracting (with respect to the resource adequacy requirement) would not allow prices to clear the energy and reserve markets. Additionally, long-term contracting should not be mandatory, and should not be based on capacity requirements but on financial hedging.

\subsection{Optimal transmission investment and market power}

A basic question is then naturally raised on how to design a mechanism that defines optimal transmission expansion depending on the market power structure of the generation sector. Sheffrin and Wolak (2001) attempt such a task by deriving the optimal expansion of the transmission network according to the strategic behavior of generators. They use a network model and California generators' bidding data to estimate bidding behavior before and after a transmission upgrade. Before an upgrade, the bid curves are classified by several peak and off peak types, either weekday or weekend/holiday so that the bids by each participant are obtained for each hour of the year. Next, the data are plugged into the SO's dispatch model to obtain the market profit outcomes. The same exercise is carried out after an upgrade, and the expected profit outcomes are calculated. This involves modeling the expected profit-maximizing bidding strategies of the generators due to the system expansion. In a related work, Wolak (2000) analyzes the optimal bidding strategy under transmission congestion of a generator that owns several generation plants.

California ISO and London Economics International (2003) (CAISO/LEI) further develop a comprehensive evaluation methodology for transmission expansion projects that incorporates the impact of strategic bidding by generators with market power. It also addresses the distributional effects of expansion between consumers and producers (and between regions), and considers the interaction between generation and transmission investment decisions. CAISO/LEI's proposal also provides a methodology to build different scenarios for a particular transmission expansion, and to assign weights to the different scenarios to help base policy decisions on expected benefits.

CAISO/LEI discuss two approaches to modeling the generator's strategic bidding behavior in transmission valuation studies. The first approach is a game-theory conjectural model with multiple bidders and exporting and importing regions. The model assumes a centralized SO that is interested in mitigating market power in generation through an adequate definition of transmission expansion projects. Considering uncertainty, as well as strategic behavior of the generators, the SO seeks to maximize social welfare as defined by the weighted sum of producer surplus and consumer surplus (the study analyzes the use of 
different weight values, such as having a zero weight value for producer surplus). Each generator makes a conjecture of the other generator's marginal cost due to the expansion. Given the predicted other bidder's supply functions, each bidder then maximizes its profits in its residual demand function.

The procedure is iterated so that participants conjecture that their competitors' bids are some function of their profit maximizing bids in previous iterations. This then sets each generator bid function, as well as the details of each iteration such as bid markups, portfolio average unit revenue, and regional prices so as to converge to stable market clearing prices (the model is deemed to have converged if players' profits do not diverge across the last two iterations by more than 1\%). Supply functions in each region for each participant are estimated, as well as changes in consumer surplus and producer surplus due to transmission upgrades. Likewise, the sensitivity of the model is checked with respect to market structure, demand, costs, and elasticities.

The second approach estimates the historical relationships between observed pricecost markups and several market variables that measure the market power of the largest suppliers, as well as the total zonal load. In the first step, Lerner indexes are regressed against the market variables. In the second step, the complete set of variables is measured according to different supply and demand scenarios. In the third step, the market-clearing prices are computed for the various supply and demand scenarios. In the final step, the new generation investment is calculated

CAISO/LEI's model is further extended to include uncertainty arising from the interdependence of demand for electricity transmission and the pattern of power generation investment. Transmission and generation can be substitutes when electricity supply is needed at a certain location, but they can also be complements since building a new transmission line might increase the volume of power that a generator can sell. Under vertical integration of generation and transmission, the integrated firm would select the minimum-cost form of supply, trading off the costs of transmission and generation investment. When generation and transmission are not integrated, the SO must forecast possible investments in generation due to new transmission investment so as to optimize the transmission investment. For each transmission upgrade option, a pattern is derived for long-run new generation entry in each congested zone. Entry is derived such that prices are kept non-negative for thermal generation plants (including peak and base-load plants).

London Economics International (2002) further utilizes a real options approach to analyze how a transmission investment process is affected by uncertain conditions on demand, costs and the possible reaction of investors in generation. Its analysis relies on the fact that a transmission investment might be delayed one or several periods. The real options model also builds on multi-scenario modeling and Monte Carlo simulations to find the joint probability distribution (for both transmission and generation) of the outcomes of transmission expansion given uncertain conditions, and the outcomes of a generation project with and without the transmission expansion. (Outcomes include prices, patterns of generation, profits, loss of load probability, and transmission losses.) The joint probability distribution is subsequently used to calculate the net present value of the transmission and generation projects. The interaction between the transmission planner (the $\mathrm{SO}$ ) and the generation investor is modeled in a game theory setup where each player has two strategies, namely "invest immediately" or "delay investment." Each investor chooses the strategy with the highest payoff given by the expected net present value and the net value of the options associated with the project. 
The CAISO/LEI model explicitly provides a methodology for selecting a representative set of market scenarios to measure benefits of a transmission expansion, and assign weighting factors to the different scenarios. Scenarios are constructed under different assumptions about natural gas prices, demand levels, hydro conditions, new generation entry, available transmission capacity, and the degree of hedging by consumers. Values for outages, age of units, imports and exports, and a time horizon of 12-15 years are included, as well as network representations for large and small transmission networks (a broad representation is enough for large networks, while a more detailed one is necessary for small networks). Both extreme and more likely scenarios are built, and weights are applied to each scenario in order to compute the expected benefits from a specific transmission expansion using a min-max optimization approach.

\subsection{Discussion on market power mechanisms}

The Sheffrin and Wolak (2001) and CAISO/LEI analyses are efforts to model the welfare loss associated with generators' price gaming under the building of a new transmission line. CAISO/LEI's conjectural model looks into price gaming, and allows a participant generator to define its own scenario for supply and demand elasticities. It calculates social welfare from price gaming to justify a new line. It explicitly addresses the existing substitution relationship between transmission and generation projects.

The results show that the benefits of transmission expansion are small until added capacity surpasses a specific upper limit that, in turn, is determined by the possibility of induced congestion by the strategic behavior of generators with market power. That is, the industry market structure plays a decisive role on the impact of a transmission upgrade. Hence, an increase in the number of generators or a redistribution of network capacity may reduce bid prices. Hedging contracts also lower bid mark-ups and prices, and high-cost bidding is very sensitive to demand elasticity for demand levels responsive to an individual generator's strategy. A transmission expansion yields benefits until it is large enough with respect to a given generation market structure. Adding cost uncertainty to the model (like environmental factors and local opposition to transmission projects) implies that many small upgrades are preferable to large greenfield projects.

The main idea behind the CAISO/LEI's model is that strategic behavior of generators will somehow self manage congestion so that the benefits of a new line result in reduced costs in both export and import zones. The price spread between zones disappears and congestion rents then shift from the transmission company to suppliers. However, the CAISO/LEI's approach relies on a transportation model with no network loop flows under the assumption that a transportation model can produce results very close to those of a power-flow model.

As argued by Hogan (2002a) the use of a transportation model in the electricity sector presents serious problems in practice since an expansion in a transmission link can imply negative externalities for certain existing transmission rights as well as a decrease in the total transmission network capacity. Thus, the typical assumption in transportation models of a monotonic behavior of the network capacity does not apply to electricity transmission.

The debate between Oren (1997) and Stoft (1999a) also addresses the use of transportation models in the electricity industry. Oren predicted from a Cournot model that generators' strategic behavior would make congestion rents go to zero, even with many competitors. Stoft pointed out defects in Oren's game formulation, including the treatment of transmission rights and the lack of realism of the Cournot model since data rejects the 
hypothesis that congestion rents go to zero. A more complicated situation arises in the presence of real market power with high concentration. In such a case, it is clear that gaming could exist, but the power-flow analysis appears to be much more complicated than the one that could be captured in a transportation model.

From a more theoretical view, Stoft (1999b) points out that multiple solutions are obtained in a Cournot setting (as in Jing-Yuan and Streets, 1999) because of the absence of markets for transmission capacity. This problem has been analytically addressed by Smeers and Jing-Yuan (1997) and Hobbs (2001) through the creation of a competitive market for transmission services within a Cournot framework. The equilibria that are discarded are ones in which there is divergence of the marginal valuations by different firms of the same transmission project.

\section{$6 \quad$ Concluding remarks}

This paper has surveyed the contributions made to the literature on the long-term expansion of the transmission network. This area has an incipient development. As Joskow and Tirole (2002) argue, the economic analysis of electricity markets has focused on shortterm issues, such as spot markets for energy, short-run congestion management, nodal pricing, and day-ahead auction rules, and has typically considered the transmission network capacity as given, fixed, and of common knowledge. However, transmission capacity is stochastic and its development mutually depends on the evolution of generation investment.

We studied the three existing approaches to electricity transmission expansion and described their analytical properties and implementation characteristics. The merchant option relies on the auction of long-term financial transmission rights by an independent system operator. This approach appears promising because it confronts the problems implied by loop flows. However, we analyzed the technical difficulties in defining an operational long-term financial transmission rights auction since loop flows could produce a result opposite to the one sought by transmission investment. Additionally, this analysis is static and at odds with the dynamic nature of transmission investment. Moreover, the existence of market power and vertical integration might jeopardize the success of this method.

"Financial Transmission rights can support merchant investment, but are inadequate to address the problems associated with large economies of scale and free riding" (Harvard Electricity Policy Group, 2002b, p. 32).

The second approach is provided by regulatory mechanisms for Transcos. The basic idea is to make a Transco confront the social cost of transmission congestion. One alternative is a two-part tariff cap that solves the opposite incentives to congest the existing transmission grid and to expand it in the long run. This approach broadens the analysis of the cost and demand functions for transmission services, which are not very well understood in the literature. However, to carry out this task, it must assume a monotonic increasing behavior of the transmission cost function. As shown by Hogan (2002b), this assumption is not (in general) valid since an expansion in a certain transmission link can lead to a total decrease of the network capacity.

In fact, there is a debate in the literature regarding the use of a regulated Transco approach for transmission expansion. On one hand, Hunt (2002) and Joskow and Tirole 
(2002) argue that a Transco regime avoids the moral-hazard-in-teams problem of an independent system operator regime. In this sense, the regulated Transco offers an advantage over the FTR/merchant approach because the Transco carries out all externality calculations and associated probability assessments, and would properly respond to incentive regulation even under loop flows (Vogelsang, 2001). On the other hand, the Transco approach faces implementation hurdles. As argued by Hogan (1999a), a Transco needs an institutional setup with one grid owner. As explained by Wolfram (1999), the Transco system like the one currently used in the United Kingdom, relies on discriminatory treatment of transmission uses. This is not acceptable in other countries such as the United States. Finally, an incentive type of regulation can hardly be implemented in meshed networks because of the impossibility of correctly defining the output of transmission.

The third alternative approach defines optimal expansion of the transmission network according to the strategic behavior of generators, and considers conjectures made by each generator on other generators' marginal costs due to the expansion. It uses a real-option analysis to calculate the net present value of both transmission and generation projects. The main contribution of this approach is that it explicitly models the existing interdependence of generation investment and transmission investment. However, it also relies on a transportation model with no network loop flows.

In summary, in both theory and practice, there is no single mechanism that guarantees the optimal expansion of the electricity transmission network. However, the studies surveyed suggest that the second-best standard suggested by Hogan (2003) may be plausible. Namely, to combine the merchant and the regulated transmission models so that "small" transmission expansion projects rely on a merchant approach while large and lumpy projects are developed through some type of incentive regulation:

"To bring coalitions together; to verify and approve the cost effectiveness of projects; and to ensure that transmission gets built in time" (Hunt, 2002, p. 206).

\section{$7 \quad$ References}

Borenstein, S. (2002) "The Trouble With Electricity Markets: Understanding California's Restructuring Disaster," Journal of Economic Perspectives, 16: 191-211.

Borenstein, S., J. Bushnell, and S. Stoft (1998) "The Competitive Effects of Transmission Capacity in a Deregulated Electricity Industry," POWER Working Paper PWP-040R. University of California Energy Institute, http://www.ucei.berkeley.edu.

Bradley, I. and C. Price (1991) "Average revenue regulation and Regional Price Structure," Regional Science and Urban Economics, 21: 89-108.

Brown L., M.A. Einhorn and I. Vogelsang (1991) "Toward Improved and Practical Incentive Regulation,” Journal of Regulatory Economics, 3: 313-338.

Bushnell, J. (1999) “Transmission Rights and Market Power," The Electricity Journal, 12: 77-85. 
Bushnell, J. B., and F. Wolak (1999) "Regulation and the Leverage of Local Market Power in the California Electricity Market," POWER Working Paper PWP-070R. University of California Energy Institute, http://www.ucei.berkeley.edu.

Bushnell, J. B., and S. E. Stoft (1996) "Electric Grid Investment Under a Contract Network Regime," Journal of Regulatory Economics, 10: 61-79.

Bushnell, J. B., and S. E. Stoft (1997) "Improving Private Incentives for Electric Grid Investment," Resource and Energy Economics, 19: 85-108.

California ISO and London Economics International (2003),"A Proposed Methodology for Evaluating the Economic Benefits of Transmission Expansions in a Restructured Wholesale Electricty Market," mimeo, http://www.caiso.com/docs/2003/03/25/2003032514285219307.

Cardell, C., C. Hitt, and W. Hogan (1997) "Market Power and Strategic Interaction in Electricity Networks," Resource and Energy Economics, 19: 109-137.

Chandley, J. D., and W. Hogan (2002) "Initial Comments of John D. Chandley and William W. Hogan on the Standard Market Design NOPR," November 11, http://www.ksg.harvard.edu/people/whogan.

Chao, H.-P., and S. Peck (1997) "An Institutional Design for an Electricity Contract Market with Central Dispatch,” The Energy Journal, 18: 85-110.

Comisión Federal de Electricidad (2000) A Market Power Analysis of Generation in Mexico, Mexico.

Crew, M. A., C.S. Fernando, and P. R. Kleindorfer (1995) "The Theory of Peak-Load Pricing: A Survey," Journal of Regulatory Economics, 8: 215-248.

Federal Energy Regulatory Commission (2002) Notice of Proposed Rulemaking. Remedying Undue Discrimination through Open Access Transmission Service and Standard Market Design, Docket No. RM01-12-000, July 31.

Fraser, R. (1995) "The relationship between the costs and prices of a multi-product monopoly: The role of price-cap regulation," Journal of Regulatory Economics, 8: 23-31.

Gilbert, R., K. Neuhoff, and D. Newbery (2002) "Mediating Market Power in Electricity Networks," mimeo.

Grande, O. S., and I. Wangensteen (2000) "Alternative Models for Congestion Management and Pricing Impact on Network planning and Physical Operation," CIGRE, Paris, Aug/Sept.

Gribik, P. R., J. S. Graves, D. Shirmohammadi, and G. Kritikson (2002) "Long Term Rights for Transmission Expansion," mimeo. 
Harvard Electricity Policy Group (2002b) Beyond Slicing and Dicing: Incentives for Transmission Owner Rapporteur's Summaries of HEPG Twenty-Eight Plenary Session, Session Three, May 30, 31.

Harvard Electricity Policy Group (2002a) "Transmission Expansion: Market Based and Regulated Approaches," Rapporteur's Summaries of HEPG Twenty-Seventh Plenary Sessions, Session Two, January 24-25.

Harvey, S. M. (2002) "TCC Expansion Awards for Controllable Devices: Initial Discussion," mimeo.

Hobbs, B. F. (2001) "Linear Complementarity Models of Nash-Cournot Competition in Bilateral and POOLCO Power Markets," IEEE Transactions on Power Systems, 16(2).

Hogan, W. (1992) "Contract Networks for Electric Power Transmission," Journal of Regulatory Economics, 4: 211-242.

Hogan, W. (1995) "To Pool or Not to Pool: A Distracting Debate," Public Utilities Fortnightly, January 1.

Hogan, W. (1999a) "Reshaping the Electricity Industry," mimeo, JFK School of Government, Harvard Electricity Policy Group Harvard University, http://www.ksg.harvard.edu/people/whogan.

Hogan, W. (1999b) "Restructuring the Electricity Market: Coordination for Competition," Mimeo, JFK School of Government, Harvard University, mimeo, Harvard Electricity Policy Group Harvard University, http://www.ksg.harvard.edu/people/whogan.

Hogan, W. (1999c) "Market-Based Transmission Investments and Competitive Electricity Markets," mimeo, JFK School of Government, Harvard Electricity Policy Group, Harvard University, http://www.ksg.harvard.edu/people/whogan.

Hogan, W. (2002a) "Financial Transmission Right Formulations," Mimeo, JFK School of Government, Harvard Electricity Policy Group Harvard University, http://www.ksg.harvard.edu/people/whogan.

Hogan, W. (2002b) "Financial Transmission Right Incentives: Applications Beyond Hedging," Presentation to HEPG Twenty-Eight Plenary Sessions, May 31, http://www.ksg.harvard.edu/people/whogan.

Hogan, W. (2002c) "Electricity Market Restructuring: Reform of Reforms," Journal of Regulatory Economics, 21: 103-132.

Hogan, W. (2003) “Transmission Market Design," mimeo, JFK School of Government, Harvard Electricity Policy Group, Harvard University, http://www.ksg.harvard.edu/people/whogan.

Hunt, S. (2002) Making Competition Work in Electricity, New York, John Wiley \& Sons. 
Jing-Yuan, W. and Y. Streets (1999) "Spatial Oligopolistic Electricity Models with Cournot Generators and Regulated Transmission Prices," Operations Research, 47: 102112.

Jordanger J, and H Grønli (2000) "Deregulation of the Electricity Supply Industry Norwegian Experience 1991-2000," The Foundation for Scientific and Industrial Research at the Norwegian Institute of Technology (SINTEF), Norway http://www.energy.sintef.no/avd/Kraftnett/Deregulation.htm.

Joskow, P. (2000) "Deregulation and Regulatory Reform in the US Electric Power Sector," mimeo, MIT.

Joskow, P. and J. Tirole (2000) "Transmission Rights and Market Power on Electric Power Networks," RAND Journal of Economics, 31: 450-487.

Joskow, P. and J. Tirole (2002) "Transmission Investment: Alternative Institutional Frameworks," mimeo.

Joskow, P. and J. Tirole (2003). Merchant Transmission Investment. mimeo.

Joskow, P. and R. Schmalensee (1983) Markets for Power: An analysis of Electric Utility Deregulation, MIT Press.

Laffont, J-J. (1989) Fundamentals of Public Economics, MIT Press.

Laffont, J-J., and J. Tirole (1993) A Theory of Incentives in Procurement and Regulation, MIT Press.

Laffont, J-J. (1994) "The New Economics of Regulation Ten Years After," Econometrica," 62: 507-537.

Léautier, T.-O. (2000) "Regulation of an Electric Power Transmission Company," The Energy Journal, 21: 61-92.

Léautier, T.-O. (2001) "Transmission Constraints and Imperfect Markets for Power," Journal of Regulatory Economics, 19: 27-54.

Littlechild, S. (2003) "Transmission Regulation, Merchant Investment, and the Experience of SNI and Murraylink in the Australian National Electricity Market," mimeo.

London Economics International (2002) "Final Methodology: Proposed Approach for Evaluation of Transmission Investment," mimeo, prepared for the CAISO.

Neu, W. (1993) "Allocative inefficiency properties of price-cap regulation," Journal of Regulatory Economics, 5: 159-182.

Oren, S. (1997) "Economic Inefficiency of Passive Transmission Rights in Congested Electricity Systems with Competitive Generation," Energy Journal, 18: 63-84. 
Pérez-Arriaga, J. I., F. J. Rubio and J. F. Puerta Gutiérrez et al. (1995) "Marginal Pricing of Transmission Services: An Analysis of Cost Recovery," IEEE Transactions on Power Systems, vol. 10, no. 1, February.

Pope, S. (2002) “TCC Awards for Transmission Expansions,” mimeo.

Ramírez, J. C. and J. Rosellón (2002) "Pricing Natural Gas Distribution in Mexico," Energy Economics, 24: 231-248.

Rosellón, J. (2003) "Pricing Electricity Transmission in Mexico," mimeo, http://www.ksg.harvard.edu/hepg/index.html.

Rubio-Odériz, J., and I. J. Pérez-Arriaga (2000). Marginal Pricing of Transmission Services: A Comparative Analysis of Network Cost Allocation Methods. IEEE Transactions on Power Systems, 15.

Sappington, D. E. M. and D. S. Sibley (1992) "Strategic nonlinear pricing under price-cap regulation," RAND Journal of Economics, 23: 1-19.

Schweppe, F., M. Caramanis, R. Tabors, and R. Bohn (1988) Spot Pricing of Electricity, Norwell, MA: Kluwer.

Secretaría de Energía (2002) Proposal for the Electrical Sector Modernization, Mexico.

Sheffrin, A. and F. A. Wolak (2001) "Methodology for Analyzing Transmission Upgrades: Two Alternative Proposals," mimeo.

Smeers, Y. and W. Jing-Yuan (1997) "Spatially Oligopolistic Model with Opportunity Cost Pricing for Transmission Capacity Reservations-A Variational Inequality Approach," Universite Catholique de Louvain, CORE Disc. Paper, 9717, Feb.

Stoft, S. (1999a) "Using Game Theory to Study Market Power in Simple Networks," IEEE Winter Power Meeting, H. Singh, Ed., Feb. 1.

Stoft, S. (1999b) "Financial Transmission Rights Meet Cournot: How TCC's Curb Market Power," The Energy Journal, 20: 1-23.

Vogelsang, I. (1999) "Optimal Price Regulation for Natural and Legal Monopolies," Economía Mexicana. Nueva Época, 8: 5-43.

Vogelsang, I. (2001) "Price Regulation for Independent Transmission Companies," Journal of Regulatory Economics, 20: 141-165.

Wilson, R. (1993) Nonlinear Pricing. New York and Oxford: Oxford University Press.

Wilson, R. (2002) “Architecture of Power Markets,” Econometrica, 70: 1299-1340.

Woolf, F. (2003) Global Transmission Expansion: Recipes for Success, Pen Well, Tulsa, Oklahoma. 
Wolak, F. A. (2000) "An Empirical Model of the Impact of Hedge Contract on Biding Behavior in a Competitive Electricity Market," International Economic Journal, 14: 1-40.

Wolfram, C. (1998) "Strategic Bidding in a Multi-Unit Auction: An Empirical Analysis of Bids to Supply Electricity in England and Wales," The RAND Journal of Economics 29: 703-725.

Wolfram, C. D. (1999) "Electricity Markets: Should the Rest of the World Adopt the UK Reforms?" Working Paper Series, POWER, University of California Energy Institute, Berkeley, http://www.ucei.berkeley.edu. 